\title{
African Americans and Network Disadvantage: Enhancing Social Capital through Participation on Social Networking Sites
}

\section{Danielle Taana Smith}

Department of Sociology and Anthropology, Rochester Institute of Technology, 21 Lomb Memorial Drive, Rochester, NY 14623, USA; E-Mail: danielle.smith@rit.edu; Tel.: +1-585-475-5133

Received: 16 January 2013; in revised form: 24 February 2013 / Accepted: 28 February 2013 / Published: 6 March 2013

\begin{abstract}
This study examines the participation of African Americans on social networking sites (SNS), and evaluates the degree to which African Americans engage in activities in the online environment to mitigate social capital deficits. Prior literature suggests that compared with whites, African Americans have less social capital that can enhance their socio-economic mobility. As such, my research question is: do African Americans enhance their social capital through their participation on SNS? I use nationally representative data collected from the Pew Internet and American Life Project to explore the research question. The results suggest that the online environment is potentially a space in which African Americans can lessen social capital deficits.
\end{abstract}

Keywords: African American; network disadvantage; social capital; social networking sites

\section{Introduction}

Since the explosion of Internet usage in the 1990s, scholars have discussed the Internet's potential to mitigate social and economic inequalities between individuals and groups. These inequalities remain persistent offline, or out of the digital arena [1]. One way in which diverse groups in society are unequal is via their social networks, and the social capital acquired through these networks. Certain groups experience a 'network disadvantage' that limits their employment opportunities, social mobility and social support, among other constraints. A common argument is that the Internet democratizes information, allows users with limited financial means to consume and produce content, and opens up educational opportunities for less privileged groups. However, a contradicting argument is that disparities that occur offline are reproduced in the online environment, such that network disadvantages remain present online [2,3]. I test these competing arguments in my evaluation of the 
degree to which social capital deficits are mitigated for African Americans by their participation on social networking sites (SNS).

African Americans are generally presented as a racial group that is network disadvantaged because they have fewer connections with workers outside of their close personal networks and thus have less access to networks that facilitate opportunities for social mobility [4]. Network disadvantage, grounded in the offline realities of social and physical segregation, can either be lessened or increased in the online environment. Given research that shows the enthusiasm with which African Americans have adopted new media [5-7], and the potential of SNS to overcome network disadvantages [8], this study addresses the question: Do African Americans enhance their social capital through their participation on social networking sites?

\section{Literature Review}

\subsection{Social Capital Accrual among African Americans}

Social capital is a powerful and wide ranging concept. It is used to understand such divergent phenomena as economic development [9], juvenile delinquency [10], health outcomes [11], employment and wage disparities [12,13], and educational attainment [14].

Three seminal formulations of social capital are found in the works of Bourdieu (1986), Coleman (1988), and Putnam (2000) [15-17]. Bourdieu [15] (1986:248) defined social capital as "the aggregate of the actual or potential resources that are linked to possession of a durable network of more or less institutionalized relationships of mutual acquaintance and recognition." Coleman [16] (1988:S98) described social capital as "a variety of entities with two elements in common: They all consist of some aspect of social structures, and they facilitate certain actions of actors-whether personal or corporate actors-within the structure." Putnam [17] (2000:67) defined social capital as "features of social organization such as networks, norms, and social trust that facilitate coordination and cooperation for mutual benefit." These conceptualizations assume that social capital is a property of the social relations in which people are embedded, and that benefits can be extracted from these social relations.

The causes and consequences of social capital can be explored at both the individual and community levels. Individual level analyses of social capital focus on the egocentric connections a given person has and the benefits that can accrue from these connections. In this network approach, benefits are often, although not solely, seen as leading to greater social mobility through employment opportunities [18]. Community level analyses examine the collective good produced through ties between individuals [19]. Focus is often placed on the number of voluntary associations [20] and measures of general levels of trust [21]. The distinction between the individual and collective levels is a matter of emphasis, as social capital can be accrued at both levels and as both levels are mutually reinforcing [22]. In this paper, I emphasize the individual level, what is often termed the network approach, and explore individual differences between African Americans and whites in the accrual of social capital from participation on SNS. The distinction between analyses at the individual and community levels is important. African Americans, at the individual level, may have strong personal networks, leading to high levels of trust, and social and emotional support within the family and among extended kin and friends. The social capital literature conceptualizes networks among people as 
strong and weak ties, each producing a different type of social capital. Affective networks are most often defined by strong ties which strengthen bonding capital between family and friends. Strong ties tend to be longer lasting and characterized by emotional intensity.

Using a broader community level approach, these same individuals with strong personal ties may receive lower levels of trust and support from other community members. Networks between people that are more professional in nature or based primarily on work related interactions are usually weaker than personal networks. More instrumental networks are conceptualized as comprising of weak ties which produce bridging capital. Networks of co-workers and other professionals exemplify weak ties. According to Putnam [17] (2000:363), "strong ties with intimate friends may ensure chicken soup when you're sick, but weak ties with distant acquaintances are more likely to produce leads for a new job." In this paper, I examine ways in which African Americans develop bonding and bridging capital and enhance their social capital through participating on social networks in online environments.

Research suggests that as compared with whites, African Americans have comparable, if not more, affective interactions with close family members and friends. However, access to the types of social capital established through professional social networks is more limited for African Americans than for whites. This network disadvantage is not unique to African Americans. In western countries, many non-white groups [23] and immigrant groups [12] have less varied social networks than do whites. The deficit in social capital is especially profound for African Americans. Studies consistently show that African Americans have fewer productive professional social networks when compared to whites [4]. For instance, Parks-Yancy [24] (2006) finds that whites have more access to social capital, and have a greater return on their social capital than do African Americans. Specifically, whites accrue higher salaries and achieve promotions faster than do African Americans.

Thus, the evidence suggests that African Americans are at a network disadvantage with respect to social capital. I can further specify this disadvantage. First, the number of networks may not be as important as the information that is shared through the networks. For example, Smith [25] (2005) argues that even when unemployed African Americans have connections to job contacts, assistance is not necessarily forthcoming. Job contacts, for fear that their reputations would be sullied by potentially poor work performance of the people they refer, often withhold valuable information. Second, this lack of social capital is not solely a working class or poor phenomenon. In research on African American managers at a Fortune 500 company, James [26] (2000) shows that African American managers reported lower levels of social capital than white managers, and that this predicted lower levels of social support for African American managers.

\subsection{Social Capital Accrual on Social Networking Sites}

Scholars have examined the capacity of the Internet and diverse online applications to reduce disparities between groups [1], such that disparities produced in the offline world can be reduced in the online world. Given offline disparities in social capital between African Americans and whites, African Americans may attempt to enhance their social capital online. Research shows that African Americans are avid users of information and communication technologies and that this motivation translates into the use of SNS [5,7]. Within this context, I focus attention on social networking sites and their potential ability to reduce the offline network disadvantage of African Americans. 
Social networking sites are "web-based services that allow individuals to (1) construct a public or semi-public profile within a bounded system; (2) articulate a list of other users with whom they share a connection; and (3) view and traverse their list of connections and those made by others within the system" (page 211 in [27]). Facebook is the most popular social networking site with more than 800 million users. Other popular SNS include MySpace, LinkedIn, LiveJournal, Pinterest, Quora, and Google+. The use of SNS tends to supplement [28] or increase [29] a user's level of social capital. It is important to also note the potential of SNS to reduce social capital. Employers and other actors with access to SNS profiles can form negative perceptions of individuals based on material posted on SNS profiles. These negative perceptions influence judgments made about individuals, including decisions whether or not to employ them.

Several studies have shown that disadvantaged groups accrue more benefits than advantaged groups when using SNS. For instance, the use of a proprietary SNS is associated with increased social capital within an organization [8]. The benefits gained are greater for newer employees, younger employees, and employees working further away from the company's headquarters. In a very different context, Mesch [30] (2012) shows that in Israel, the generally disadvantaged Arab-Israeli minority are more likely to use the Internet to augment their social capital than the Israeli majority. These two studies conclude that SNS usage can help both individuals and groups who are structurally disadvantaged to meet diverse needs and objectives.

\section{Data and Methods}

\subsection{Data}

I use nationally representative data to examine differences between African Americans and whites, the majority racial group in the United States. The data comes from the Pew Internet and American Life's "Spring Tracking Survey 2008". The Pew Internet and American Life Project conducts research that explores the impact of the Internet on individuals, families, communities, and on social, economic, political and religious institutions. The survey was conducted between 8 April 2008 and 8 May 2008 through telephone interviews of a random sample of adults age 18 or over. The survey asks questions about respondents' Internet activities and attitudes towards technology. The response rate is $25 \%$. The total number of respondents is 2251, with African American respondents numbering 215. The Pew provides a weight for this survey derived from the Census Bureau's March 2007 Annual Social and Economic Supplement to correct for response bias [31].

\subsection{Dependent Variables}

The Pew survey asks respondents several questions that are related to social networking activity. Descriptive statistics for these variables are presented in Table 1. I use seven measures of social capital based on these activities. First, I determine whether or not a respondent reported currently having a profile on an SNS. I consider having a profile a measure of social capital since an important function of SNS is to strengthen social networks among members of the site. This rationale is consistent with Mesch [30] (2012:323), who argues that: 
"Whereas chat rooms and forums are technologies that link individuals around a shared topic of interest and concern, SNS are technologies that link individuals who have some knowledge of each other and belong to the same social circle or to the social circle of their friends... Given these features of channels of communication, it is reasonable to expect that the motivation for the use of chat rooms and weblogs is to expand social ties and the use of SNS to conserve existing ties."

The next three measures focus on enhancing social capital through participating in affective activities on SNS. These affective measures are: "Do you stay in touch with friends?", "Do you make plans with your friends?", and "Do you make new friends?" These activities focus directly on affective relations that contribute to the establishment of strong personal networks.

Fifth, I measure whether or not a respondent has profiles on multiple SNS. Having multiple profiles is included as a measure of social capital because if the objective is to strengthen social ties, then one site is usually sufficient to maintain relationships with other site members the individual shares strong ties with. Having a single profile conforms to the prevailing notion of what a social networking site is - one community where friends remain in touch. Metcalfe [32] (1995) observes that a network becomes more valuable with more users. Close friends tend to join the same network, or in this case, the same SNS. Friends who are on an SNS with very few connections will ultimately join the larger network because this has more value in the sense that it allows more communication with more close friends.

If a person joins several social networking sites, it suggests that this person is searching for unique pools of information, and the objective is more than or different from maintaining contact with people they already know. For example, a site like Facebook may suffice for enhancing strong ties with close friends and family. However, a person joins a professional website such as LinkedIn to expand professional networks, which enhances professional social capital.

The sixth and seventh measures assess the level of social capital accrued through professional networks. These professional measures are: "Do you make new business or professional contacts?", and "Do you promote yourself or your work?" Given the work related nature of these activities, they can be thought of as direct attempts to enhance professional social capital.

Table 1. Descriptive statistics for dependent variables (\% in Parentheses).

\begin{tabular}{cccc}
\hline Social capital activities & N & No & Yes \\
\hline Do you have an SNS profile? & 2251 & $1913(85)$ & $338(15)$ \\
Stay in touch with friends? & 326 & $43(13.2)$ & $283(86.8)$ \\
Make plans with your friends? & 327 & $150(45.9)$ & $177(54.1)$ \\
Make new friends? & 328 & $157(51.8)$ & $326(48.2)$ \\
Do you have more than one SNS profile? & 314 & $175(55.7)$ & $139(44.3)$ \\
Make new business and professional contacts? & 326 & $233(71.5)$ & $93(28.5)$ \\
Promote yourself or your work? & 327 & $237(72.5)$ & $90(27.5)$ \\
\hline
\end{tabular}

\subsection{Independent Variables}

The independent variables for the analyses represent standard demographic and socioeconomic predictors and are presented in Table 2. I include income and education as measures of socio-economic status. I also include gender and age. These variables have all been recognized to significantly affect Internet usage. Finally, with the exception of the ethnoracial status variable, all other variables are 
treated as controls. I expect that these controls will influence the accrual of social capital, and I am interested in differences between African Americans and whites.

Table 2. Univariate statistics for independent variables.

\begin{tabular}{cccc}
\hline Variable & Frequency & Variable & Frequency \\
\hline Education $(\mathbf{N}=\mathbf{2 2 2 0})$ & \multicolumn{2}{c}{ Ethnoracial status $(\mathbf{N}=\mathbf{2 1 9 1})$} \\
\hline Less than High School & 8.9 & White & 81.8 \\
High School & 32.3 & Black & 9.8 \\
Some College & 26.0 & Hispanic & 4.8 \\
College Graduate & 32.7 & Other & 3.6 \\
\hline Income $(\mathbf{N}=\mathbf{1 7 5 5})$ & \multicolumn{3}{c}{ Gender } \\
\hline Less than $\$ 20,000$ & 17.2 & Male & 45.5 \\
Between $\$ 20,000$ and $\$ 40,000$ & 24.2 & Female & 54.5 \\
Between $\$ 40,000$ and $\$ 100,000$ & 41.2 & - & - \\
Over $\$ 100,000$ & 17.5 & - & - \\
\hline- & Continuous variables \\
Age & Mean & SD \\
\hline & 55.1 \\
\hline
\end{tabular}

\subsection{Methods}

Since the dependent variables are presented as "yes" or "no" questions, such that $1=$ yes, and $0=$ no, I use binary logistic regression to determine the net effect of being African American on social networking activity. An odds ratio greater than 1 for an independent variable indicates that the variable's effect is to increase the odds of "yes". Conversely, an odds ratio of less than 1 indicates that the variable's effect is to decrease the odds of "yes". Values above 1 represent percentage point increases, and values below 1 represent percentage point decreases. Similar to parameter estimates for ordinary least squares regression analysis, an odds ratio for nominal variables show an increase in odds compared to the reference variable. For example, consider a model predicting the ownership of multiple social networking profiles, with the reference group being respondents with incomes between $\$ 40,000.00$ and $\$ 100,000.00$. If I observe an odds ratio of 0.459 for income between $\$ 20,000.00$ and $\$ 40,000.00$, then I can interpret this observation as: "The odds of having profiles on multiple social networks for respondents with incomes between $\$ 20,000.00$ and $\$ 40,000.00$ are $54 \%$ less than for respondents with incomes between $\$ 40,000.00$ and $\$ 100,000.00$."

One measure is ordinal: how many sites does the respondent have profiles on? However, given the bi-modal distribution of this variable (not shown), I chose to recode it as dichotomous. For each variable, I present the odds ratio of being in one category of the dependent variable (coded 1) as opposed to being in the other category (coded 0 ).

\section{Results and Discussion}

This analysis allows an examination of whether or not, as compared with whites, being African American is associated with an increase in activities on social networking sites that enhance social capital accrual for African Americans. Results are shown in Table 3. 
Table 3. Binary logistic regressions for social capital measures.

\begin{tabular}{|c|c|c|c|c|c|c|c|}
\hline Measures of social capital & $\begin{array}{c}\text { Have SNS } \\
\text { profile? }\end{array}$ & $\begin{array}{l}\text { Stay in touch } \\
\text { with friends? }\end{array}$ & $\begin{array}{c}\text { Make plans } \\
\text { with friends? }\end{array}$ & $\begin{array}{l}\text { Make new } \\
\text { friends? }\end{array}$ & $\begin{array}{l}\text { More than } \\
\text { one profile? }\end{array}$ & $\begin{array}{c}\text { Make new } \\
\text { business } \\
\text { contacts? }\end{array}$ & $\begin{array}{c}\text { Promote } \\
\text { yourself or } \\
\text { your work? }\end{array}$ \\
\hline Variable & Odds-Ratio & Odds-Ratio & Odds-Ratio & Odds-Ratio & Odds-Ratio & Odds-Ratio & Odds-Ratio \\
\hline Age & $0.915^{* * *}$ & $0.947 * * *$ & $0.971 * * *$ & 0.997 & $0.989^{*}$ & $1.02 * * *$ & $1.01^{*}$ \\
\hline \multirow[t]{2}{*}{ Female } & $1.29 * * *$ & 1.47 & 0.931 & $0.612 * * *$ & $0.546 * * *$ & $0.357 * * *$ & $0.355^{* * *}$ \\
\hline & \multicolumn{7}{|c|}{ Income $^{1}$} \\
\hline Less than $\$ 20,000$ & $1.48 * * *$ & 1.17 & 1.13 & $1.98 * * *$ & $1.70 * *$ & $0.667 *$ & $0.584 * *$ \\
\hline Between $\$ 20,000$ and $\$ 40,000$ & 0.989 & $2.18^{*}$ & $0.469 * * *$ & $0.705^{*}$ & $0.446^{* * *}$ & 0.786 & 0.828 \\
\hline \multirow[t]{2}{*}{ Over $\$ 100,000$} & 0.835 & $0.450 * *$ & 0.739 & $0.346^{* * *}$ & $0.444 * * *$ & 1.05 & 0.885 \\
\hline & \multicolumn{7}{|c|}{ Education $^{2}$} \\
\hline Less than High School & $1.52 * * *$ & $3.01 * *$ & 1.17 & 1.16 & $0.518^{* *}$ & 0.882 & $2.11 * * *$ \\
\hline Some College & $2.11 * * *$ & $10.02 * * *$ & $2.05 * * *$ & 0.748 & 0.969 & 1.26 & 1.14 \\
\hline \multirow[t]{2}{*}{ College Graduate } & $1.96 * * *$ & 1.05 & $.343 * * *$ & $.429 * * *$ & 1.07 & 1.35 & 1.21 \\
\hline & \multicolumn{7}{|c|}{ Ethnoracial status $^{3}$} \\
\hline White & $1.32 *$ & 1.80 & 0.845 & 0.875 & $0.585^{* *}$ & $0.265^{* * *}$ & $0.279 * * *$ \\
\hline Hispanic & $1.73 * * *$ & 1.41 & 0.883 & 0.998 & $0.620^{*}$ & $0.387 * * *$ & $0.480^{* *}$ \\
\hline Other & $1.73 * *$ & 0.811 & $0.250 * * *$ & $0.427 * *$ & 0.711 & $0.130 * * *$ & $0.418^{* *}$ \\
\hline Constant & 4.28 & 22.58 & $5.97 * * *$ & $2.56^{* * *}$ & $3.11 * * *$ & 0.994 & 1.11 \\
\hline Nagelkerke $\mathrm{R}^{2}$ & 0.359 & 0.294 & 0.241 & 0.153 & 0.102 & 0.134 & 0.120 \\
\hline $\mathrm{N}$ & 2251 & 326 & 327 & 328 & 314 & 326 & 317 \\
\hline
\end{tabular}

$* p<.05 ; * * p<.01 ; * * * p<.001 ; 1-$ Between $\$ 40,000$ and $\$ 100,0000$ as Reference Category; 2-High School as Reference Category; 3 -African American as Reference Category.

For the question of having an SNS profile, older respondents are less likely to have an SNS profile; a year increase in age is associated with $0.085 \%$ decrease in the odds of having an SNS profile. Females are more likely to have an SNS profile, with the odds of a woman having an SNS profile being $29 \%$ greater than the odds of a male having a profile. There is not much difference between income groups, although respondents in poverty are more likely to have an SNS profile than respondents making between $\$ 40,000.00$ and $\$ 100,000.00$ annually. Turning my attention to race, African Americans are less likely to report having an SNS profile than are whites. Specifically, the odds of a white respondent reporting that they have an SNS profile is $32 \%$ more than the odds of an African American reporting that they have an SNS profile.

I also measured three affective activities that enhance social capital: staying in touch with friends, making plans with friends, and making new friends. For most of the control variables, older respondents are less likely to report performing these activities. Middle income respondents, those making between $\$ 40,000.00$ and $\$ 100,000.00$, are in general more likely to report performing affective activities, with the exception being when compared with those making less than $\$ 20,000.00$. There is no clear pattern regarding education. Respondents with less than a high school degree and those with some college education are more likely to perform these activities, while those with a college degree are less likely to perform these activities. There is very little difference between African Americans and whites for the three affective activities. 
Regarding the fifth measure, having multiple SNS profiles, age is again negatively associated with having multiple SNS profiles. Gender is also significant, as females are $45 \%$ less likely than males to have multiple profiles. Income is significantly associated with this measure. However, this association is not consistent. Those in the lowest income category (less than $\$ 20,000.00$ ) are more likely than the reference group (between $\$ 40,000.00$ and $\$ 100,000.00$ ) to have multiple profiles, but respondents in the next highest income category are less likely to have multiple profiles than the reference group. As both of these categories have lower income than the reference category, I cannot summarize and state that income has a positive or negative effect based on the data. Education has very little association with having multiple SNS profiles. Only high school respondents reported significant levels of having more than one profile than the reference category. For race, African Americans are $41 \%$ more likely than whites to report having more than one profile.

Three clear patterns relate to the sixth and seventh measures, the professional activities of making new business contacts and promoting yourself or your work. First, contrary to other measures, age is positively related to these measures. Second, males are more likely to report performing these professional activities. Females are 64\% less likely to make new business contacts and promote themselves or their work. Third, the socio-economic variables of income and education have little effect on professional activities, as compared to the affective activities of staying in touch with friends; making plans with friends; and making new friends.

I also observe clear patterns with respect to race. The odds of a white respondent reporting making new business contacts is $74 \%$ less than the odds of an African American respondent reporting such, and the odds of a white respondent reporting that they promoted themselves or their work is $72 \%$ less than the odds of an African American reporting self and work promotion.

I initially questioned whether as compared with whites, being African American will be associated with more activities that enhance social capital on social networking sites. The results support an affirmative conclusion. Being African American is associated with an increased likelihood over whites for the professional activities of "promoting yourself at work", "making business contacts", and "owning more than one profile". One qualification is that African Americans are less likely to own an SNS profile than are whites.

\section{Conclusions}

Research focusing exclusively on African Americans and their usage of information and communication technologies is relatively scant. In general, African Americans are considered to be members of the "have nots" in the digital age. However, current research suggests that African Americans have positive attitudes towards technology [5,7], and are likely to use technologies to accomplish everyday activities [33]. These studies provide understanding as to how African Americans appropriate technologies to navigate their social worlds. Similarly, I argue that African Americans may not always be the disadvantaged group regarding the use of technologies, as suggested by the digital divide paradigm.

The findings from this study illustrate the complexity of information and communication technologies usage and the need to look beyond general economic and technological indicators - measures that lend themselves to labeling minorities as "have nots", and to focus on needs and objectives that influence 
the activities and experiences of individuals and groups in the digital environment. On the one hand, this study shows that African Americans are less likely to own a social networking site profile than are whites. Yet, when they do elect to own a profile, they are just as likely as are whites to perform activities that enhance their affective social networks, including staying in touch with friends, making plans with friends and making new friends. Further, African Americans are far more likely than are whites to perform professional activities that enhance their social capital, including making new business and professional contacts, and promoting themselves or their work. While I do not conclusively state that African Americans accrue more social capital from their social network usage than do whites, I do suggest the potential of SNS to mitigate social capital deficits for African Americans.

On a practical level, I observe how offline disadvantages can potentially be addressed through online activities. African Americans are more socially and physically segregated than are other groups in the United States, which is an important reason why they have lower levels of social capital than do whites. The online environment, with its arguably lesser regard for time, space, and cultural context, provides African Americans with a potential mechanism through which their network disadvantages can be lessened. These findings add to the growing consensus that online social networking can mitigate offline network disadvantage [8,30]. I focused on African Americans in this study. More studies are needed which determine the degree to which other minority groups also take advantage of the online environment to lessen offline inequalities.

\section{References}

1. Mehra, B.; Merkel, C.; Peterson Bishop, A. The Internet for empowerment of minority and marginalized users. New Media Soc. 2004, 6, 781-802.

2. Waggoner, A.; Smith, E.; Collins, E. Person perception by active versus passive perceivers. J. Exp. Soc. Psychol. 2009, 45, 1028-1031.

3. Weisbuch, M.; Ivcevic, Z.; Ambady, N. On being liked on the web and in the "real world": Consistency in first impressions from personal webpages and spontaneous behavior. $J$. Exp. Soc.Psychol. 2009, 45, 573-576.

4. Parks-Yancy, R.; DiTomaso, N.; Post, C. How does tie strength affect access to social capital resources for the careers of working and middle class African-Americans? Crit. Sociol. 2009, 35, $541-563$.

5. Correa, T.; Jeong, S. Race and online content creation: Why minorities are actively participating in the web. Inf. Commun. Soc. 2010, 14, 638-659.

6. Graham, R. ICT as cultural practice: Group differences in attitudes towards technology among Americans. New Media Soc. 2010, 12, 985-1003.

7. Graham, R.; Smith, D. Internet as digital practice: Differences in African American internet activity. Future Internet 2011, 3, 185-203.

8. Steinfield, C.; DiMicco, J.; Ellison, N.; Lampe, C. Bowling online: Social networking and social capital within the organization. In Proceedings of the Fourth International Conference on Communities and Technologies, New York, NY, USA, 25-27 June 2009; pp. 245-254.

9. Kaminska, M. Bonding social capital in a postcommunist region. Am. Behav. Sci. 2010, 53, 758-777. 
10. Spencer, J.; Irwin, K.; Umemoto, K.; Garcia-Santiago, O.; Nishimur, S.; Hishinuma, S.; Choi-Misailidis, S. Exploring the hypothesis of ethnic practice as social capital: Violence among Asian/Pacific Islander youth in Hawaii. Int. J. Soc. Psychiatry 2009, 55, 506-524.

11. Huijts, T.; Kraaykamp, G. Formal and informal social capital and self-rated health in Europe: A new test of accumulation and compensation mechanisms using a multi-level perspective. Acta Sociol. 2012, 55, 143-158.

12. Behtoui, A.; Neergard, A. Social capital and wage disadvantages among immigrant workers. Work Employ. Soc. 2010, 24, 761-779.

13. Parzefall, M.; Kuppelwieser, V. Understanding the antecedents, the outcomes and the mediating role of social capital: An employee perspective. Human Relat. 2012, 65, 447-472.

14. Menahem, G. The impact of community bonding and bridging social capital on educational performance in Israel. Urban Educ. 2011, 46, 1100-1130.

15. Bourdieu, P. The forms of capital. In Handbook of Theory and Research for the Sociology of Education; Richardson, J., Ed.; Greenwood: New York, NY, USA, 1986; pp. 241-258.

16. Coleman, J. Social capital in the creation of human capital. Am. J. Soc. 1988, 94, S95-S120.

17. Putnam, R. Bowling Alone: The Collapse and Revival of American Community; Simon and Schuster: New York, NY, USA, 2000.

18. McDonald, S.; Elder, G., Jr. When does social capital matter? Non-searching for jobs across the life course. Soc. Forces 2006, 85, 521-549.

19. Kawachi, I.; Kennedy, B.; Glass, R. Social capital and self-rated health: A contextual analysis. Am. J. Public Health 1999, 89, 1187-1193.

20. Okayasu, I.; Kawahara, Y.; Nogawa, H. The relationship between community sport clubs and social capital in Japan: A comparative study between the comprehensive community sport clubs and the traditional community sports clubs. Int. Rev. Sociol. Sport 2010, 45, 163-186.

21. Keele, L. Social capital and the dynamics of trust in government. Am. J. Polit. Sci. 2007, 51, 241-254.

22. Lin, N. Social Capital: A Theory of Social Structure and Action; Cambridge University Press: Cambridge, UK, 2001.

23. Moren-Cross, J.; Lin, N. Access to social capital and status attainment in the United States: Racial/Ethnic and gender differences. In Social Capital: An International Research Program; Lin, N., Erickson, B., Eds.; Oxford University Press: Oxford, UK, 2008; pp. 364-379.

24. Parks-Yancy, R. The effects of social group membership and social capital resources on careers. J. Black Stud. 2006, 36, 515-545.

25. Smith, S. "Don't put my name on it": Social capital activation and job finding assistance among the black urban poor. Am. J. Sociol. 2005, 111, 1-57.

26. James, E. Race-related differences in promotions and support: Underlying effects of human and social capital. Organ. Sci. 2000, 11, 493-508.

27. Boyd, D.; Ellison, E. Social network sites: Definition, history, and scholarship. J. Comput.Mediat. Commun. 2007, 13, 210-230.

28. Lee, J.; Lee, H. The computer-mediated communication network: Exploring the linkage between the online community and social capital. New Media Soc. 2010, 12, 711-727. 
29. Benkler, Y. The Wealth of Networks: How Social Production Transforms Markets and Freedom; Yale University Press: New Haven, CT, USA, 2007.

30. Mesch, G. Minority status and the use of computer-mediated communication: A test of the social diversification hypothesis. Commun. Res. 2012, 39, 317-337.

31. Pew Internet and American Life (2008). Spring Tracking Survey. Available online: http://www.pewinternet.org/Reports/2008/Podcast-Downloading-2008/Questions-and-Data/SpringTracking-Survey-2008.aspx (accessed on 4 January 2013).

32. Metcalfe, B. Metcalfe's law: A network becomes more valuable as it reaches more users. InfoWorld 1995, 17, 53.

33. Smith, A. Mobile Access 2010; Pew Internet \& American Life Project: Washington, DC, USA, 2010. Available online: http://www.pewinternet.org/Reports/2010/Mobile-Access-2010.aspx (accessed on 4 January 2013).

(C) 2013 by the authors; licensee MDPI, Basel, Switzerland. This article is an open access article distributed under the terms and conditions of the Creative Commons Attribution license (http://creativecommons.org/licenses/by/3.0/). 